\title{
Bioleaching of Manganese Oxides at Different Oxidation States by Filamentous Fungus Aspergillus niger
}

\author{
Bence Farkas ${ }^{1}$, Marek Bujdoš ${ }^{1}$, Filip Polák ${ }^{2}$, Michaela Matulová ${ }^{1}$, Martin Cesnek ${ }^{3}$, Eva Duborská ${ }^{1}$, \\ Ondřej Zvěřina $\left.{ }^{4}{ }^{(}\right)$, Hyunjung Kim ${ }^{5,6}{ }^{\oplus}$, Martin Danko ${ }^{7}$, Zuzana Kisová ${ }^{8}$, Peter Matúš ${ }^{1}$ and Martin Urík ${ }^{1, * \mathbb{C}}$ \\ 1 Institute of Laboratory Research on Geomaterials, Faculty of Natural Sciences, Comenius University in \\ Bratislava, Mlynská Dolina, Ilkovičova 6, 84215 Bratislava, Slovakia; farkas62@uniba.sk (B.F.); \\ marek.bujdos@uniba.sk (M.B.); michaela.matulova@uniba.sk (M.M.); eva.duborska@uniba.sk (E.D.); \\ peter.matus@uniba.sk (P.M.) \\ 2 Department of Soil Science and Soil Protection, Czech University of Life Sciences Prague, Kamýcká 129, \\ 16500 Praha-Suchdol, Czech Republic; polakf@af.czu.cz \\ 3 Department of Nuclear Reactors, Faculty of Nuclear Sciences and Physical Engineering, Czech Technical \\ University in Prague, V Holešovičkách 2, 18000 Prague, Czech Republic; martin.cesnek@ffifi.cvut.cz \\ 4 Department of Public Health, Faculty of Medicine, Masaryk University, Kamenice 753/5, \\ 62500 Brno, Czech Republic; zverina@med.muni.cz \\ 5 Department of Mineral Resources and Energy Engineering, Jeonbuk National University, \\ Jeonju-si 54896, Korea; kshjkim@jbnu.ac.kr \\ 6 Department of Environment and Energy, Jeonbuk National University, Jeonju-si 54896, Korea \\ 7 Polymer Institute, Slovak Academy of Sciences, Dúbravská Cesta 9, 84541 Bratislava, Slovakia; \\ upoldan@savba.sk \\ check for \\ updates \\ Citation: Farkas, B.; Bujdoš, M.; \\ Polák, F.; Matulová, M.; Cesnek, M. \\ 8 Institute of Molecular Biology, Slovak Academy of Sciences, Dúbravská Cesta 21, 84551 Bratislava, Slovakia; \\ zuzana.kisova@savba.sk \\ * Correspondence: martin.urik@uniba.sk
} Duborská, E.; Zvěřina, O.; Kim, H.; Danko, M.; Kisová, Z.; et al. Bioleaching of Manganese Oxides at Different Oxidation States by Filamentous Fungus Aspergillus niger. J. Fungi 2021, 7, 808. https://doi.org/ 10.3390/jof7100808

Academic Editors: Elisabet Aranda and Ramón Alberto Batista-García

Received: 6 August 2021

Accepted: 22 September 2021

Published: 28 September 2021

Publisher's Note: MDPI stays neutral with regard to jurisdictional claims in published maps and institutional affiliations.

Copyright: (C) 2021 by the authors Licensee MDPI, Basel, Switzerland. This article is an open access article distributed under the terms and conditions of the Creative Commons Attribution (CC BY) license (https:/ / creativecommons.org/licenses/by/ $4.0 /)$.

\begin{abstract}
This work aimed to examine the bioleaching of manganese oxides at various oxidation states $\left(\mathrm{MnO}, \mathrm{MnO} \cdot \mathrm{Mn}_{2} \mathrm{O}_{3}, \mathrm{Mn}_{2} \mathrm{O}_{3}\right.$ and $\mathrm{MnO}_{2}$ ) by a strain of the filamentous fungus Aspergillus niger, a frequent soil representative. Our results showed that the fungus effectively disintegrated the crystal structure of selected mineral manganese phases. Thereby, during a 31-day static incubation of oxides in the presence of fungus, manganese was bioextracted into the culture medium and, in some cases, transformed into a new biogenic mineral. The latter resulted from the precipitation of extracted manganese with biogenic oxalate. The Mn(II,III)-oxide was the most susceptible to fungal biodeterioration, and up to $26 \%$ of the manganese content in oxide was extracted by the fungus into the medium. The detected variabilities in biogenic oxalate and gluconate accumulation in the medium are also discussed regarding the fungal sensitivity to manganese. These suggest an alternative pathway of manganese oxides' biodeterioration via a reductive dissolution. There, the oxalate metabolites are consumed as the reductive agents. Our results highlight the significance of fungal activity in manganese mobilization and transformation. The soil fungi should be considered an important geoactive agent that affects the stability of natural geochemical barriers.
\end{abstract}

Keywords: bioextraction; bioleaching; filamentous fungi; manganese oxide; oxalate

\section{Introduction}

Manganese is a transition metal that is the 10th most abundant chemical element on Earth and makes up to $0.1 \%$ of the Earth's crust. It is a structural component of more than 250 minerals and, in the case of several other minerals, is a substituent of $\mathrm{Fe}^{2+} \mathrm{and} \mathrm{Mg}^{2+}$ cations [1].

Manganese occurs in various oxidation states of which the $+\mathrm{II},+\mathrm{III}$ and $+\mathrm{IV}$ are predominant under natural conditions [2]. In the soil environment, it occurs in dissolved form, and it is partially adsorbed onto the surface of non-manganese mineral phases or organic compounds, or it is immobilized in organisms. Most of the manganese in the soil is 
found as a component of primary mineral phases or is bound to secondary minerals [3]. Baranowsky et al. [4] showed that soil manganese is primarily associated with fractions of carbonates and metal oxides. However, significant amounts can also be found in residues left after sequential extraction. A similar distribution has been found in sediments, where the manganese was reported to be bound mostly to carbonates and hydrated oxides $[5,6]$.

Manganese oxides and (oxo)hydroxides are among the most common secondary minerals of manganese in the soil. These are reactive phases that play an important role in the geochemical cycling of various elements. They generally participate in redox transformations of organic and inorganic compounds, since they represent the strongest oxidizing agents found in the environment [7].

As an essential nutrient, manganese is involved in various cellular functions such as redox homeostasis, metabolism of sugars and protein synthesis; and it is incorporated in vital molecules such as vitamin B or Mn-superoxide dismutase [8]. However, it becomes hazardous upon exposure to high concentrations with severe adverse impacts on plants and soil microorganisms [9]. Therefore, upon exposure to elevated concentrations, microorganisms are capable of utilizing various strategies to immobilize manganese to limit its bioavailability [10].

The biosynthesis of manganese oxides in soils and sediments contributes to the formation of geochemical barriers, the high sorption and redox capacity of which can significantly decrease the mobility of potentially toxic elements in the environment [11]. Since the stability of manganese oxides is essential for limiting the spread of contamination, the microbially induced biodeterioration of these phases [2] should be studied in great detail, and carefully monitored in soils, especially in regard to the activity of various geoactive agents of biological origin [12-14]. First, however, controlled laboratory-scale experiments are required for a better understanding of the processes leading to the manganese oxides' deterioration.

Our research is therefore based on the assumption that the $\mathrm{MnO}, \mathrm{MnO} \cdot \mathrm{Mn}_{2} \mathrm{O}_{3}, \mathrm{Mn}_{2} \mathrm{O}_{3}$ and $\mathrm{MnO}_{2}$, which are constituents of naturally occurring geochemical barriers, should react differently with the metabolites of Aspergillus niger, a common soil filamentous fungus. We evaluated the contribution of the fungus to the chemical biodeterioration of manganese oxides using advanced analytical and mineralogical techniques. They allowed us to observe the kinetics of this fundamental process and led us to a better understanding of mechanisms that microorganisms employ to affect the manganese geochemistry in the environment.

\section{Materials and Methods}

\subsection{Fungal Strain}

The fungus Aspergillus niger strain CBS 140837 was obtained from the fungal collection of the Department of Mycology and Physiology at the Institute of Botany, Slovak Academy of Sciences. The fungal strain was maintained on the Sabouraud agar plates at $25{ }^{\circ} \mathrm{C}$.

\subsection{Manganese Toxicity}

The manganese 50\% inhibitory concentration for the fungal radial growth was examined using various concentrations of manganese(II) $\left(100 ; 250 ; 450 ; 650\right.$ and $\left.1000 \mathrm{mg} \cdot \mathrm{L}^{-1}\right)$, prepared by dissolving $\mathrm{MnCl}_{2} \cdot 4 \mathrm{H}_{2} \mathrm{O}$ (Centralchem, Bratislava, Slovakia) in the Sabouraud Dextrose Agar (HiMedia, Mumbai, India). The media were inoculated with $A$. niger strain and were cultivated at $25^{\circ} \mathrm{C}$ for 7 days. We measured the radial growth of the fungus daily, and it was used to calculate the fungal growth parameters using the modified Gompertz growth equation [15]. Then, the 50\% inhibitory concentration for the selected growth parameter was estimated using probit analysis.

\subsection{Bioextraction of Manganese}

The 31-day long manganese extraction experiments using the $A$. niger strain were performed in $100 \mathrm{~mL}$ sterile Erlenmeyer flasks with the mixture of $50 \mathrm{~mL}$ Sabouraud Dextrose Broth culture medium (HiMedia, Mumbai, India) and $0.635 \mathrm{~g}$ of $\mathrm{MnO}, 0.600 \mathrm{~g}$ of $\mathrm{MnO} \cdot \mathrm{Mn}_{2} \mathrm{O}_{3}, 0.826 \mathrm{~g}$ of $\mathrm{Mn}_{2} \mathrm{O}_{3}$, or $0.844 \mathrm{~g}$ of $\mathrm{MnO}_{2}$. However, the initial extraction tests 
were performed with the $0.250 \mathrm{~g}$ weight of each manganese oxide for a period of 21 days. The manganese oxides in various oxidation states $\left(\mathrm{MnO}, \mathrm{MnO}_{2}, \mathrm{Mn}_{2} \mathrm{O}_{3}\right.$ and $\mathrm{MnO} \cdot \mathrm{Mn}_{2} \mathrm{O}_{3}$ ) were obtained from Sigma-Aldrich (Darmstadt, Germany).

To inoculate the growth media, a spore suspension was produced by washing the surface of a 10-day-old $A$. niger culture with sterile water, and approximately $10^{5} \mathrm{CFU}$ were used as inoculum. Prior to inoculation, the manganese oxides in $100 \mathrm{~mL}$ Erlenmeyer flasks were sterilized by dry heating and, after sterilization, the culture medium was added. The control experiments were performed using a manganese oxide-free cultivation of fungus or non-inoculated control.

All experiments were carried out under laboratory conditions for the 31-day long static cultivation that allowed fungus to reach the stationary growth phase. During the cultivation, the $\mathrm{pH}$ of the culture medium, as well as the dissolved manganese and organic acid content, were determined 21 times over the cultivation period. The spent medium was filtered, and the $\mathrm{pH}$ was recorded. The harvested biomass was collected, washed with distilled water, sonicated and mechanically treated to remove residual manganese oxalate crystals, dried in a laboratory oven at $70^{\circ} \mathrm{C}$ and weighed. Furthermore, the structural and morphological properties of mineral phases collected at the end of cultivation were characterized. In the case of the initial 21-day long tests, only the total extracted manganese was measured in the culture medium.

\subsection{Analytical Procedures}

The culture media filtrates were analyzed for the total manganese content by flame atomic absorption spectroscopy (F AAS) at line Mn $279.5 \mathrm{~nm}$ using an AAS spectrometer Perkin-Elmer Model 1100 (Perkin-Elmer, Uberlingen, Germany). Deuterium background correction was used. Calibration solutions were prepared from CertiPUR ICP $1000 \mathrm{mg} \cdot \mathrm{L}^{-1}$ single-element standard solutions (Merck, Darmstadt, Germany). To confirm the method's accuracy, the CRM Astasol AN9090MN (aqueous multi-element standard solution, Analytika, Praha, Czech Republic) was used. The CRM's quantification was within the certified ranges. The precision of the method was $4 \%$ for Mn (relative combined standard uncertainty with coverage factor $\mathrm{k}=2$ ).

The low-molecular-weight organic acids in the culture medium were analyzed by capillary isotachophoresis. Analysis of anions in $10 \mathrm{~mL}$ filtrate $(0.45 \mu \mathrm{m})$ from the culture medium collected in the desired time intervals was performed by a ZKI 01 isotachophoretic analyzer (Villa Labeco, Spišská Nová Ves, Slovakia) using the itp-itp mode. The $10 \mathrm{mmol} \cdot \mathrm{L}^{-1}$ hydrochloric acid adjusted with $\beta$-alanine to $\mathrm{pH} 4.25$ plus $0.1 \%$ methylhydroxylethylcellulose was used as the leading electrolyte, and $5 \mathrm{mmol} \cdot \mathrm{L}^{-1}$ caproic acid with histidine was used as the terminating electrolyte. For the quality control, a Quality Control Standard (QCS) was analyzed before each batch sample analysis. QCS (200 $\mu \mathrm{M}$ oxalate, citrate, gluconate, acetate) was prepared by dilution of $1000 \mathrm{mg} \cdot \mathrm{L}^{-1}$ batch solutions of anions (TraceCERT Oxalate, Citrate, Gluconate, Acetate IC Standards; Sigma Aldrich, Saint-Louis, MO, USA). The isotachopherograms were evaluated by the analyzer supplied with ITPWin ver. 2.30 software [16] (Villa Labeco, Spišská Nová Ves, Slovakia).

Manganese oxides and their transformants were analyzed by high energy X-ray diffraction (HEXRD). The experiment was performed at beamline P02.1 of PETRA III electron storage ring (DESY, Hamburg, Germany). Energy of the beam was set to $E=59.73091 \mathrm{keV}$ $(\lambda=0.20757 \AA)$. The samples were put into Kapton tubes with a diameter of $1 \mathrm{~mm}$ and were illuminated by an incident beam that had a cross section of $0.5 \mathrm{~mm} \times 0.5 \mathrm{~mm}$. All the diffraction patterns were collected at room temperature using a two-dimensional detector Perkin Elmer $1621(2048 \times 2048$ pixels, pixel size $200 \mu \mathrm{m} \times 200 \mu \mathrm{m})$. The sample-to-detector distance (SDD) was set to $1285 \mathrm{~mm}$. A $\mathrm{CeO}_{2}$ standard was used to calibrate SDD and the relative tilt of the detector to the incident beam path. Two-dimensional diffraction patterns were integrated using FIT2D software ver. 18, developed at the European Synchrotron Radiation Facility (ESRF, Grenoble, France). The Match!3 software ver. 3.12 (Crystal Impact, Bonn, Germany) was used to compare the diffraction pattern of samples to reference 
patterns included in the Crystallography Open Database to identify the phases present before and after cultivation.

The complex data analysis was performed using Analysis ToolPak and Solver, statistical add-ins in Microsoft Office Excel (Redmond, WA, USA). Manganese extraction performances by the fungus were compared via $t$-test (two-sample assuming unequal variances) at a significance level $\alpha=0.01$.

\section{Results}

\subsection{Fungal Resistance to Manganese(II) and Manganese Oxides}

The $A$. niger strain was tested for its resistance to manganese by measuring the fungal colony growth on agar media. There, the fungus was exposed to up to $1000 \mathrm{mg} \cdot \mathrm{L}^{-1}$ of manganese(II). Its sensitivity resulted in a decrease in colony growth rate $\left(\mathrm{cm} \cdot \mathrm{day}^{-1}\right)$, and the lag phase was prolonged (Figure 1). The test concluded in the determination of $50 \%$ colony growth inhibitory concentration at $330 \mathrm{mg} \cdot \mathrm{L}^{-1}$.

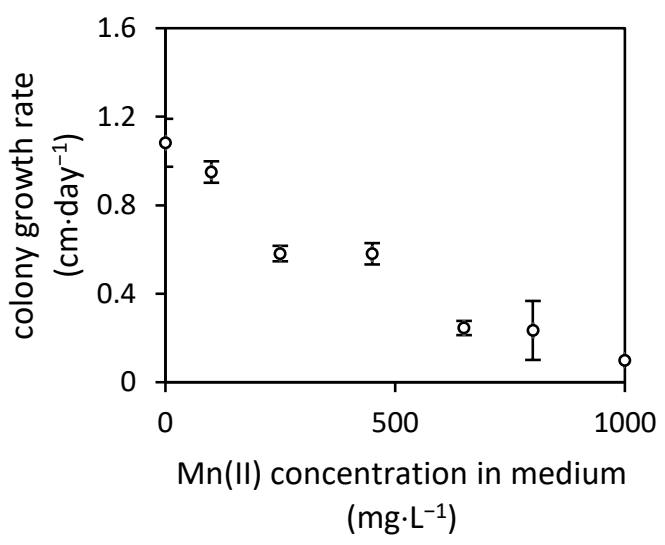

(a)

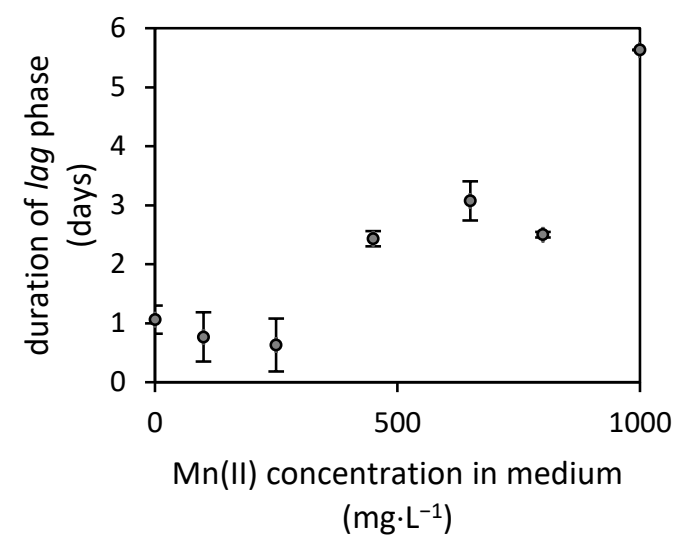

(b)

Figure 1. The effects of dissolved manganese(II) concentrations in agar media on (a) the colony growth rate of Aspergillus niger strain and (b) the duration of lag phase. The lag phase was estimated using modified Gompertz's equation [15].

The sensitivity of the $A$. niger strain to oxides and bioextracted manganese can be evaluated using the recorded changes of dry weights of fungal biomasses (Figure 2). The biomass harvested from the $\mathrm{Mn}$ (II)-oxide (MnO) treatment almost achieved the weight of the manganese-free control at the end of cultivation. It was followed by the biomass cultivated in the presence of the $\mathrm{Mn}(\mathrm{IV})$-oxide $\left(\mathrm{MnO}_{2}\right)$ and $\mathrm{Mn}(\mathrm{II})$-oxide. The least amounts of biomasses were recorded in the presence of $\mathrm{Mn}(\mathrm{II}, \mathrm{III})$-oxide $\left(\mathrm{MnO} \cdot \mathrm{Mn}_{2} \mathrm{O}_{3}\right)$. The length of lag phase of each treatment, which was calculated along the maximum growth rate using the modified Gompertz's equation [15], indicated when a considerable cell division and, thus, the exponential growth phase occurred. It was the longest for the fungus cultivated in the presence of $\mathrm{Mn}$ (II)-oxide (2.3 days), followed by the $\mathrm{Mn}(\mathrm{IV})$-oxide treatment (2.0 days). In the presence of $\mathrm{Mn}(\mathrm{II}, \mathrm{III})$-oxide and $\mathrm{Mn}$ (III)-oxide $\left(\mathrm{Mn}_{2} \mathrm{O}_{3}\right)$, the exponential growth phase was achieved by the fungus significantly faster, after a day. The maximum growth rate was reduced only in the presence of $\mathrm{Mn}$ (II)-oxide $\left(0.03 \mathrm{day}^{-1}\right)$. The rates estimated in the presence of all other oxides approximated the growth rate of fungus cultivated on manganese-free media $\left(0.05\right.$ day $\left.^{-1}\right)$.

\subsection{Manganese Bioextraction}

The efficiencies of manganese bioextraction from various manganese oxides $(\mathrm{MnO}$, $\mathrm{MnO} \cdot \mathrm{Mn}_{2} \mathrm{O}_{3}, \mathrm{Mn}_{2} \mathrm{O}_{3}$ and $\mathrm{MnO}_{2}$ ) by filamentous fungus $A$. niger were initially examined for the even $0.25 \mathrm{~g}$ weight of each oxide. The collected data, presented in Figure 3, revealed that the $\mathrm{Mn}(\mathrm{II}, \mathrm{III})$-oxide was the most susceptible to fungal deterioration, approximating 
$69 \%$ extraction efficiency. The Mn(III)-oxide was the most stable with less than $27 \%$ of manganese extracted after the 21-day cultivation.

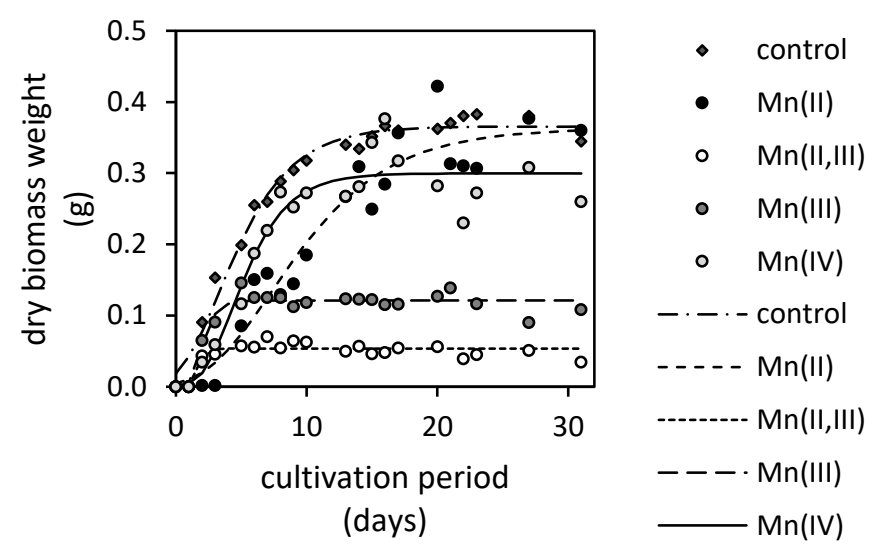

Figure 2. Changes in biomass weight of Aspergillus niger cultivated for 31 days in the culture medium supplemented with various manganese oxides $\left(\mathrm{MnO}, \mathrm{MnO} \cdot \mathrm{Mn}_{2} \mathrm{O}_{3}, \mathrm{Mn}_{2} \mathrm{O}_{3}\right.$ and $\mathrm{MnO}_{2}$; control is a manganese-free treatment). Experimental data were fitted using modified Gompertz's equation [15].

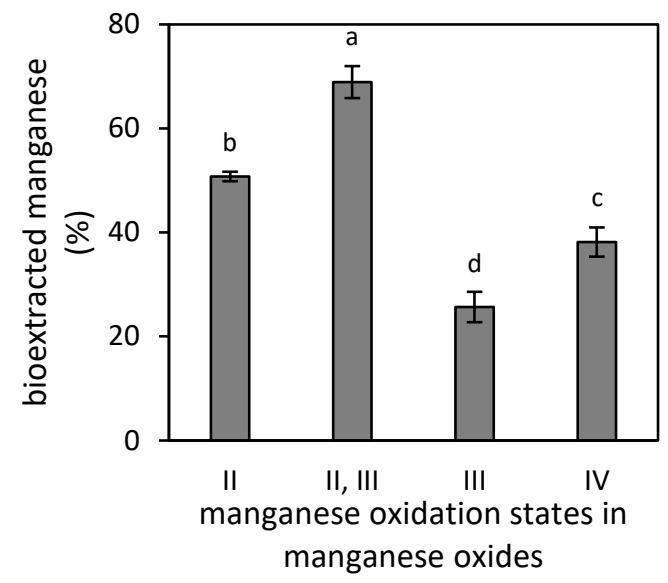

Figure 3. Bioextraction of manganese from its oxides ( $\mathrm{MnO}, \mathrm{MnO} \cdot \mathrm{Mn}_{2} \mathrm{O}_{3}, \mathrm{Mn}_{2} \mathrm{O}_{3}$ and $\mathrm{MnO}_{2}$ ) by microscopic filamentous fungus Aspergillus niger after a 21-day cultivation (initial weigh of each oxide was $0.25 \mathrm{~g}$ in $50 \mathrm{~mL}$ of culture medium; the extraction efficiencies were compared for all treatments via two-tail $t$-test at the 0.01 significance level).

The values of bioextraction efficiency along the calculated 50\% inhibitory concentration were further used as reference values to calculate the initial amount of each oxide for further evaluation of bioextraction kinetics. In effect, the oxides' weight that included the total amount of $330 \mathrm{mg}$ manganese was increased by the non-extractable manganese estimated from Figure 3. The calculated amounts of oxides were subsequently supplemented in broth media and were exposed to growing fungus.

Figure 4 depicts that the filamentous fungus $A$. niger was capable of mobilizing manganese from all oxides. Since the extraction efficiencies in non-inoculated control during a 31-day experiment were negligible, it was concluded that the manganese oxides' deterioration and subsequent stabilization of extracted manganese in solution resulted solely from fungal activity.

The extraction kinetics revealed various distinctive phases that are similar to the characteristics of microbial growth. The slow initial phase is followed by the steep increase in manganese extraction that is subsequently diminished after the 10th cultivation day (Figure 4). These are the general features of Mn(II,III), Mn(III) and Mn(IV)-oxides' biodeterioration. There, the Mn(II,III)-oxide was the most susceptible to fungal activity, reaching the $26 \%$ extraction efficiency $\left(2340 \mathrm{mg} \cdot \mathrm{L}^{-1}\right)$. It was followed by $\mathrm{Mn}(\mathrm{II}), \mathrm{Mn}(\mathrm{III})$ 
and Mn(IV)-oxides, which did not display a statistically significant difference in maximum amounts of extracted manganese due to high variabilities in observed values. However, the average maximums of manganese in culture medium were 1210,1140 and $700 \mathrm{mg} \cdot \mathrm{L}^{-1}$ for $\mathrm{Mn}(\mathrm{II}), \mathrm{Mn}(\mathrm{III})$ and $\mathrm{Mn}(\mathrm{IV})$-oxides, respectively.

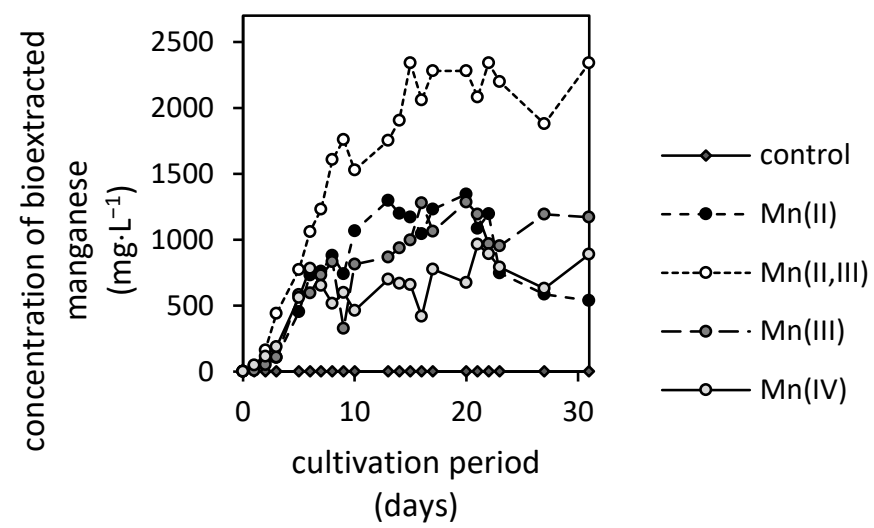

Figure 4. Concentrations of bioextracted manganese from its oxides ( $\mathrm{MnO}, \mathrm{MnO} \cdot \mathrm{Mn}_{2} \mathrm{O}_{3}, \mathrm{Mn}_{2} \mathrm{O}_{3}$ and $\mathrm{MnO}_{2}$ ) at different oxidation states during the static cultivation of microscopic filamentous fungus Aspergillus niger.

The deterioration of $\mathrm{Mn}$ (II)-oxide featured the specific phase where the manganese concentrations seemingly decreased in the medium. This was characteristic in the late growth phase of the fungus and coincided well with other measured growth parameters, including biomass weight, $\mathrm{pH}$ and depletion of extracellular low-molecular-weight organic acids.

\subsection{Changes in $\mathrm{pH}$ and Concentrations of Low-Molecular-Weight Organic Acids in the Presence of Manganese Oxides}

During the 31-day cultivation, fungus $A$. niger was capable of producing the extractioninducing extracellular metabolites to various extents. These, in the course of time, have changed the qualitative and quantitative parameters of culture media, ultimately altering the extraction performance of fungus towards each manganese oxide. Capillary isotachophoresis revealed that, during cultivation, the low-molecular-weight organic acids of oxalate and gluconate were primarily produced by the fungus.

The concentration of oxalate accumulated in the culture medium, after being exposed to $\mathrm{Mn}(\mathrm{II})$-oxide, reached its maximum of $11 \mathrm{mM}$ on the 6 th day of cultivation. Thereafter, the oxalate concentration in the culture medium steeply decreased and remained relatively stable for the rest of the cultivation (Figure 5). A similar pattern, with slightly lower extracellular oxalate concentrations, was also observed after exposure to $\mathrm{Mn}$ (III) and $\mathrm{Mn}(\mathrm{IV}$ )-oxides (Figure 5). No oxalate was detected in the presence of $\mathrm{Mn}$ (II,III)-oxide. It is also worth mentioning that the accumulation of oxalate in the culture medium was significantly higher in a manganese-free treatment, and it reached the maximum concentration of $56 \mathrm{mM}$.

The presence of acetate was noted only in culture media supplemented with the $\mathrm{Mn}(\mathrm{IV}$ )-oxide (Figure 6). In all other treatments, the fungus did not produce any acetate, or it was consumed/degraded during the cultivation. Alternatively, its concentration was below the detection limit of the applied analytical procedure.

Notable changes in the concentration of gluconate have been observed after exposure to various manganese oxides (Figure 7). The fungus was capable of accumulating and metabolizing gluconate to various extents during cultivation. The apparent gluconate accumulation was the lowest in the case of the manganese-free control, while the highest concentration in the culture medium was observed in the Mn(II,III)-oxide treatment (over a $100 \mathrm{mM}$ concentration). Since gluconate anions are derived from glucose extracellularly and are subsequently uptaken, it is likely that the synthesized gluconate in the case of 
the control experiment was completely metabolized in later growth phases and, thus, no gluconate was detected in the culture medium after the 22nd day of cultivation.

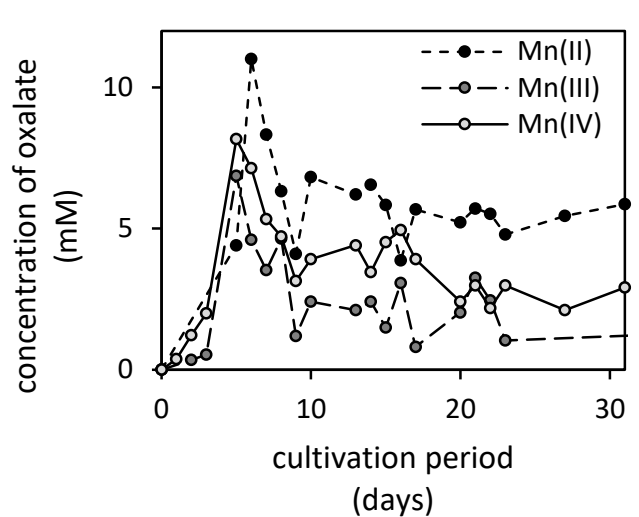

(a)

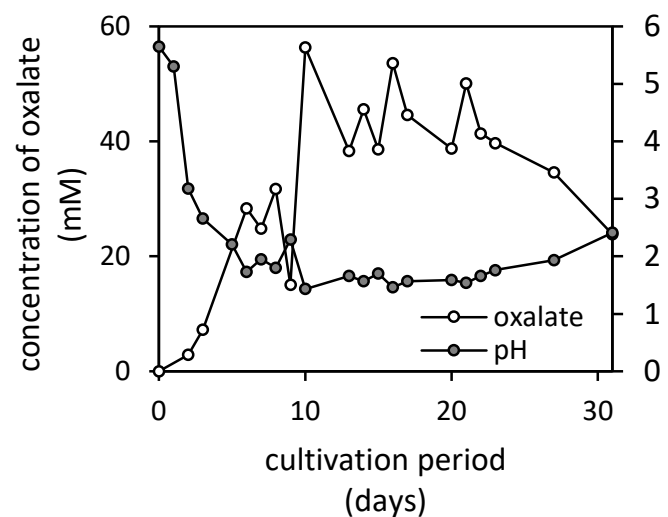

(b)

Figure 5. Changes of oxalate concentrations in culture media supplemented with (a) Mn(II); Mn(III) and Mn(IV)-oxides, and (b) changes of $\mathrm{pH}$ and oxalate concentrations in manganese-free treatment (control) during a 31-day cultivation of fungus Aspergillus niger.

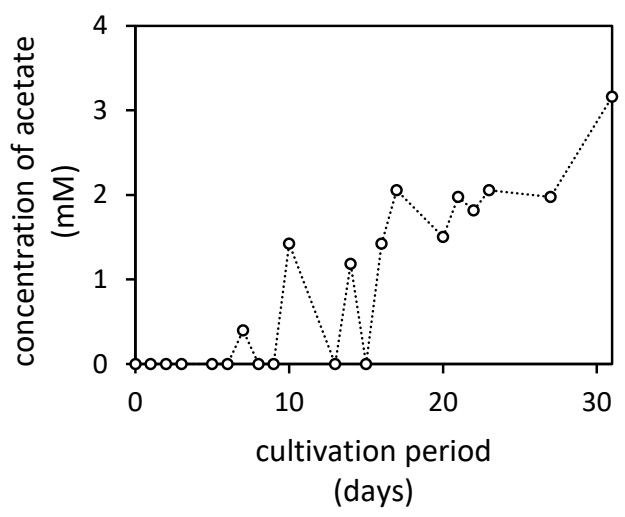

Figure 6. Changes in acetate concentration in culture medium supplemented with $\mathrm{Mn}(\mathrm{IV})$-oxide $\left(\mathrm{MnO}_{2}\right)$ incubated in the presence of Aspergillus niger for 31 days. The concentration of acetate in other treatments was below the detection limit $(0.004 \mathrm{mM})$ of applied analytical procedure.

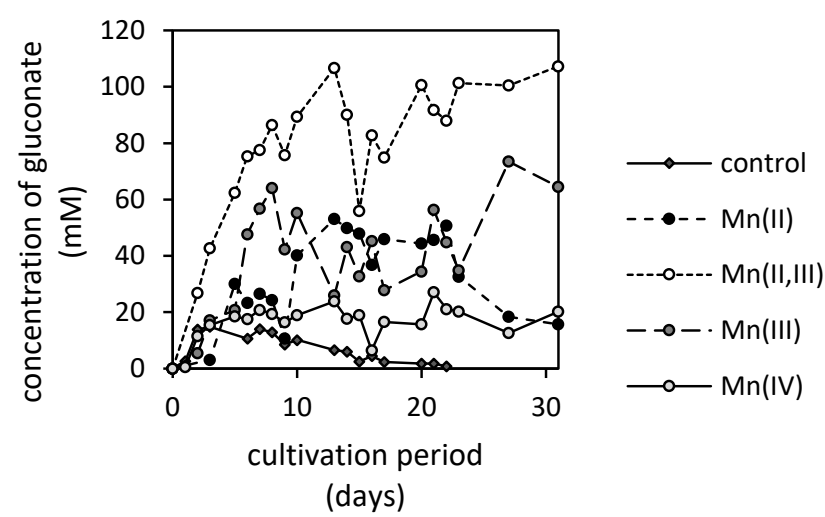

Figure 7. Changes in gluconate concentration in culture medium supplemented with various manganese oxides ( $\mathrm{MnO}, \mathrm{MnO} \cdot \mathrm{Mn}_{2} \mathrm{O}_{3}, \mathrm{Mn}_{2} \mathrm{O}_{3}$ and $\mathrm{MnO}_{2}$ ) incubated in the presence of Aspergillus niger for 31 days (control is a manganese-free treatment).

Significant depletion of gluconate after three weeks was also noted in the case of $\mathrm{Mn}$ (II)-oxide, where the $50 \mathrm{mM}$ of gluconate decreased within a few days below $20 \mathrm{mM}$ concentration. The $\mathrm{Mn}$ (III)-oxide led to a higher accumulation of gluconate in the early and 
late stages of fungal growth, approximating 64 and $73 \mathrm{mM}$ concentrations, respectively. The exposure of fungus to $\mathrm{Mn}(\mathrm{IV})$-oxide activated extensive gluconate utilization, thus, its concentration in the medium was low and relatively stable with values reaching up to $18 \mathrm{mM}$ (Figure 7).

The culture media $\mathrm{pH}$ in the presence of manganese oxides fluctuated between the values of six and three (Figure 8). Initial acidification within the first five days provided ideal conditions for (reductive) dissolution of manganese oxides (Figure 4). Thereafter, the $\mathrm{pH}$ gradually increased with $\mathrm{Mn}(\mathrm{II}, \mathrm{III})$ and $\mathrm{Mn}(\mathrm{IV})$-oxides, reaching a $\mathrm{pH}$ of five on the 16th day of cultivation. The $\mathrm{pH}$ values of culture media treated with $\mathrm{Mn}$ (II) and $\mathrm{Mn}(\mathrm{III})$-oxides ascended to the value of five significantly slower. The manganese-free treatment indicated inhibitory effects of manganese on proton exudation since it decreased its $\mathrm{pH}$ below the value of two and remained so almost until the end of cultivation. There, it increased to the value of 2.4 .

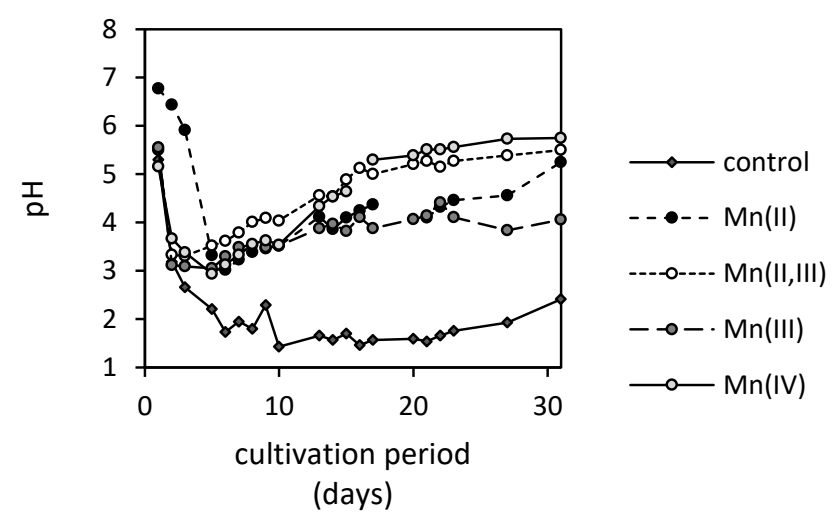

Figure 8. Changes in $\mathrm{pH}$ of culture medium supplemented with various manganese oxides $(\mathrm{MnO}$, $\mathrm{MnO} \cdot \mathrm{Mn}_{2} \mathrm{O}_{3}, \mathrm{Mn}_{2} \mathrm{O}_{3}$ and $\mathrm{MnO}_{2}$ ) incubated in the presence of Aspergillus niger for 31 days (control is a manganese-free treatment).

\subsection{Formation of Biogenic Mineral}

During the cultivation, a large crystal formation in the biomass of microscopic filamentous fungus was observed (Figure 9). It was most apparent in media supplemented with $\mathrm{Mn}(\mathrm{IV})$ and $\mathrm{Mn}$ (II)-oxides, while the exposure of fungus to $\mathrm{Mn}$ (III) and $\mathrm{Mn}$ (II,III)oxides did not result in the detectable formation of new mineral phases. While the initial crystallinity of $\mathrm{Mn}(\mathrm{II}), \mathrm{Mn}(\mathrm{II}, \mathrm{III})$ and $\mathrm{Mn}(\mathrm{III})$-oxides was relatively high, the sample of $\mathrm{Mn}(\mathrm{IV})$-oxide was less ordered, and it included amorphous phases and a small fraction of manganese-oxides at different oxidation states as well (Figure 10).

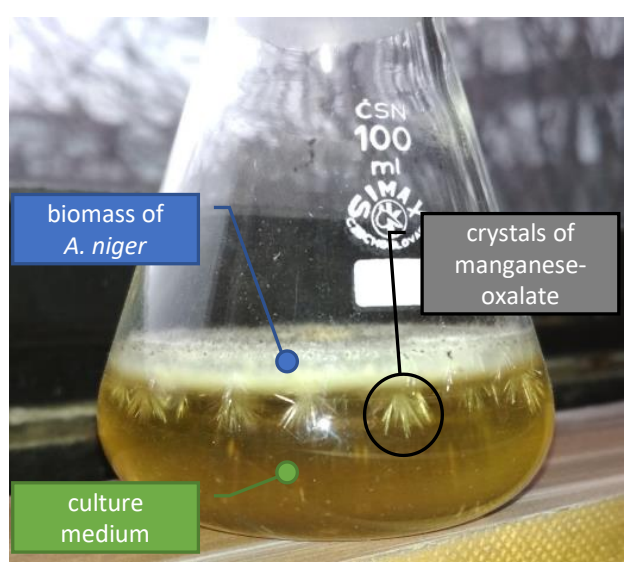

Figure 9. The biogenic manganese oxalate crystals associated with the fungal biomass of filamentous fungus Aspergillus niger cultivated in the presence of $\mathrm{Mn}(\mathrm{IV})$-oxide. 

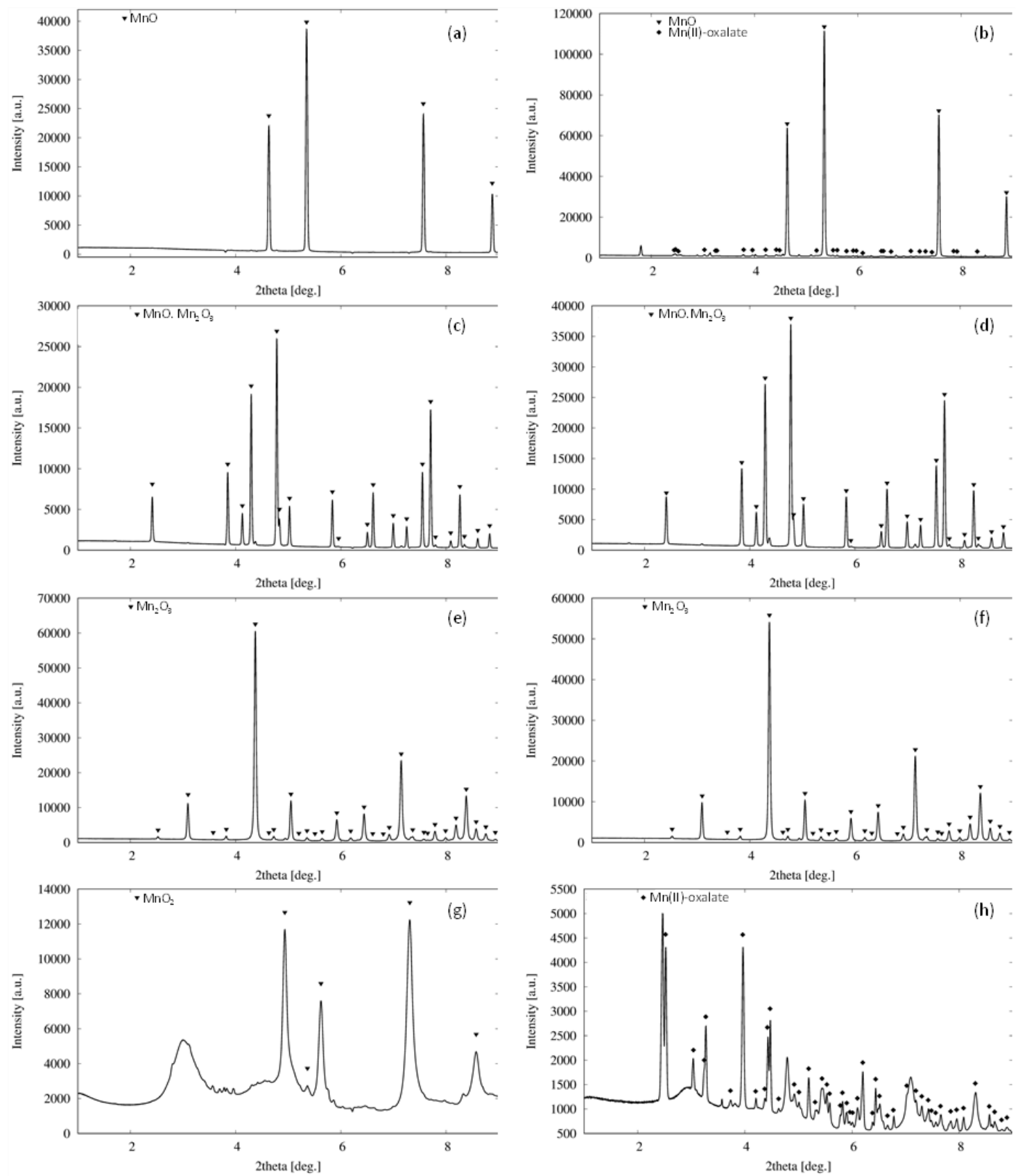

Figure 10. High energy (synchrotron) X-ray diffraction of $\mathrm{Mn}(\mathrm{II}), \mathrm{Mn}(\mathrm{II}, \mathrm{III}), \mathrm{Mn}(\mathrm{III})$ and $\mathrm{Mn}(\mathrm{IV})$-oxides (a,c,e,g) at the initiation of a 31-day incubation in the presence of filamentous fungus Aspergillus niger, and (b,d,f,h) at the end of cultivation in respective order.

The formation of crystals was noticeable after the seventh cultivation day (Figure 9), and it correlated well with the decrease and fluctuations of oxalates' concentrations in the culture media (Figure 5). There, the extracted manganese and accumulated oxalate concentrations reached the required amounts for precipitation of new biomineral phases. The newly formed crystals were analyzed by synchrotron X-ray diffraction analysis at the end of cultivation, and they were identified as manganese oxalates (Figure 10). Thus, the formation of manganese oxalates during the cultivation experiments was confirmed in systems supplemented with $\mathrm{Mn}(\mathrm{IV})$ and $\mathrm{Mn}(\mathrm{II})$-oxides. 


\section{Discussion}

Our results (Figure 4) highlighted that the fungus A. niger was capable of rapid disintegration of naturally occurring manganese oxides. Since the abiotically extracted manganese did not reach the culture medium concentration of $0.15 \mathrm{mg} \cdot \mathrm{L}^{-1}$ in the noninoculated control, we have concluded that the oxides are highly stable in near-neutral abiotic systems, and the fungal strain's presence is essential for the extensive mobilization of manganese. In the case of Mn(II,III)-oxide, the fungus was capable of dissolving $26 \%$ of manganese within the 31-day cultivation. This resulted in its significant accumulation in the culture medium, reaching a concentration of $2340 \mathrm{mg} \cdot \mathrm{L}^{-1}$.

Since the fungus has shown a capacity to solubilize metal oxides that are natural components of geochemical barriers $[17,18]$, its activity in the environment has various undesired impacts. The severity of this process is underlined by the fact that manganese oxides serve as a natural scavenger of various potentially toxic compounds, as well as trace metals in soils and sediments [19]. Thus, our research, which confirmed the fungal ability to dissolve all of the naturally occurring manganese oxides, emphasizes the potential negative impacts of fungal activity in contaminated soils and sediments regarding the mobility of hazardous elements [20].

On the other hand, the solubilization of manganese oxides by filamentous fungi shows immense potential for the recovery of manganese from discarded low-grade manganiferous ores since it is considered a better green alternative to pyrometallurgical and hydrometallurgical techniques [21]. Archarya et al. [22] studied the bioleaching of manganese ore ( $2 \%$ $w / v)$ using culture solutions of Penicillium citrinum strain. The secreted fungal metabolites were capable of removing $19.6 \%$ of manganese within a period of 30 days. This is similar to the extraction performance of $A$. niger in our study. However, Mehta et al. [23] reported that the $A$. niger strain was capable of extracting up to $91 \%$ of manganese from oceanic polymetallic nodules $(5 \% w / v)$. The reported bioleaching efficiency highlighted the potential of $A$. niger for manganese bioextraction from environmental samples. This process was recently optimized by Keshavarz et al. [24] for the bioleaching of low-grade pyrolusite (pulp density of $1 \mathrm{~g} \cdot \mathrm{L}^{-1}$ ) with the extraction maximum of $78.8 \%$ achieved through a twostep method using the medium collected after 21 days of dynamic cultivation (120 rpm) of fungus in the glucose medium. The strains of Aspergillus section Nigri also proved to be an efficient extractor of manganese from Mn-Zn batteries [25]. Still, none of these studies distinguished the effect of the manganese oxidation state on bioextraction performance, which is reported in our study. However, in contrast to all other referred studies, our experimental leaching of manganese oxides was performed under static conditions as a one-step method. It is very likely that the static cultivation hindered the mobility of nutrients and the aeration of media, thus, the fungal activity could be altered unfavorably in comparison to dynamic cultivation. Furthermore, the two-step bioextraction method is more advantageous, since the direct exposure to extracted manganese through the one-step method adversely affected the fungal growth (Figure 2). Still, in the case that the fungal growth was not affected, the extraction performance of the two-step method under both dynamic and static conditions tends to be similar [14]. Nevertheless, the indirect exposure of manganese phases to fungal metabolites via the two-step method is most likely the main reason why the experimental methods of other authors outperformed our extraction efficiency.

One of the principal mechanisms of manganese mobilization seems to be the synthesis of extracellular low-molecular-weight organic acids with exceptional chelating and acidic properties [26]. However, fungi usually excrete these in the dissociated form since the intracellular $\mathrm{pH}$ is at neutral levels [27]. Therefore, the extremely low $\mathrm{pH}$ of the extracellular environment (below 3.5, Figure 8) should coincide with the intensive fungal extrusion of $\mathrm{H}^{+}$to maintain the neutral intracellular $\mathrm{pH}$ [28].

Based on our previous experiences, we assumed that, besides proton extrusion, the oxalate would be the key metabolite in the disintegration of manganese oxide minerals [17,29]. Therefore, the outcome that the Mn(II,III)-oxide was the most intensively biodeteriorated, despite no oxalate being produced by the fungus during incubation, was unexpected. 
Since oxalate accumulation in the medium was one magnitude higher in the manganese oxide-free treatment compared to other systems (Figure 5b), and extreme acidification of media should reportedly not contribute to the enhancement of oxalate synthesis [30], we concluded that the presence of high manganese concentration was the primary factor that inhibited oxalate efflux from the fungal cell. Thus, the absence of oxalate in the Mn(II,III)-oxide treatment was likely caused by the excessive release of manganese via acidolysis.

This should allow us to conclude that it is very likely that the acidification of culture media played a key role in manganese oxides' dissolution. However, our observations also suggest an alternative or co-occurring pathway of manganese oxides' deteriorationa reductive dissolution. Xyla et al. [31] noted that, during the extraction of manganese from $\mathrm{Mn}(\mathrm{IV})$-oxide $\left(\beta-\mathrm{MnO}_{2}\right)$, the oxalate and oxide are consumed in a ratio of $1: 1$. The protons are also consumed; thus, the manganese(II) release from $\mathrm{Mn}(\mathrm{IV})$-oxide follows the Equation (1):

$$
\mathrm{MnO}_{2}(\mathrm{~s})+\mathrm{C}_{2} \mathrm{O}_{4}{ }^{2-}+4 \mathrm{H}^{+} \leftrightarrow \mathrm{Mn}^{2+}+2 \mathrm{CO}_{2}+2 \mathrm{H}_{2} \mathrm{O}
$$

Therefore, the reductive dissolution of Mn(IV)-oxide is facilitated under acidic conditions and by the occurrence of oxalate. Oxalate forms a precursor surface complex that results in an electron transfer and a release of the reduced manganese(II) ion to the solution [31]. This explains the high extraction efficiency at higher $\mathrm{pHs}$ and at apparent oxalate absence in a medium supplemented with $\mathrm{Mn}(\mathrm{II}, \mathrm{III})$-oxide in the presence of a fungus.

There are also reports suggesting the direct involvement of enzymatic activity in redox transformation of manganese by filamentous ascomycetes. Miyata et al. [32] reported that the Acremonium KR21-2 strain was capable of oxidizing dissolved Mn(II) via the activity of a laccase- or multicopper oxidase-like protein that is distinct from the basidiomycete laccases [33]. Recently, Zeiner et al. [34] revealed the presence of both Cu-based and FAD-based Mn(II) oxidation mechanisms in various ascomycete species and suggested candidates for oxidases, including tyrosinase, glyoxal oxidase, bilirubin oxidase, and glucose-methanol-choline oxidoreductase. The oxidative transformation of $\mathrm{Mn}$ (II) should lead to the deposition of (biogenic) Mn(III/IV)-oxides [35]. However, besides biogenic oxalates, no other new mineral phases have been detected in the presence of $\mathrm{Mn}(\mathrm{II}), \mathrm{Mn}(\mathrm{II}, \mathrm{III})$ and $\mathrm{Mn}(\mathrm{III})$-oxides (Figure 10). While enzymatic reductive dissolution of manganese oxides is characteristic primarily for bacterial species [36], filamentous fungi most likely mediated the reduction of manganese non-enzymatically [37], for example, via oxalate or citrate [31,38,39].

Exposure of fungus to excessive amounts of manganese also alters the apparent gluconate accumulation in the medium, however, inversely to oxalate (Figure 7). It is well known that gluconate is derived from glucose due to glucose oxidase activity [40], and it can serve as an easily utilizable carbon source for $A$. niger [41]. The gluconate synthesis at a $\mathrm{pH}$ lower than 3.5 is significantly inhibited, since the enzyme's activity is dependent on external $\mathrm{pH}$ [42] with an optimum at $\mathrm{pH} 6$ [43]. This is in good agreement with our experimental findings (Figure 7), where the accumulation of gluconate was insignificant in the case of manganese-free treatment with the lowest $\mathrm{pH}$ level. On the other side, the highest accumulation in the medium was observed in the cultivating system treated with Mn(II,III)oxide, where the $\mathrm{pH}$ was almost continuously above the value of 3.5 (Figure 8). However, this can also indicate the negative impact of manganese on the metabolism of external carbon sources. It can be concluded that the rate of gluconate production is similar to that of gluconate uptake by biomass in the manganese-free treatment. Since the latter is not strictly dependent on the control mechanism as carbon catabolite repression [44], it is very likely that the significantly higher accumulation in culture media supplemented with Mn-oxides resulted from the unknown mechanism restricting gluconate uptake by fungus in manganese excess.

During the cultivation, the growth of biogenic crystals associated with the biomass of filamentous fungus was noted. The formation of crystals was observable from the seventh cultivation day and is associated with apparent fluctuation in free oxalate concentrations 
in the medium (Figure 5). There, the dissolved manganese and oxalate concentrations reached the required level for nucleation and subsequent biogenic mineral growth into a detectable manganese oxalate crystal associated with the biomass (Figure 9). Similarly, Ferrier et al. [45] identified the presence of lindbergite (manganese oxalate dihydrate) in the solid phases, forming sheaths around the hyphae of $A$. niger cultivated in the presence of manganese-rich deep-sea nodules. It was most apparent in culture media supplemented with Mn(IV)-oxide (Figure 9), followed by the Mn(II)-oxide, while for all other cases it was unnoticeable. The absence of crystal formation in $\mathrm{Mn}$ (II,III) and $\mathrm{Mn}$ (III)-oxide treatments can be explained by the extensive consumption of oxalate due to reductive dissolution.

Furthermore, the ability to form mineral oxalates provides the fungus with an ecological advantage in contaminated soils and sediments. There, the oxalates can serve as a detoxification agent due to their sorptive properties and ability to coprecipitate some of the heavy metals, including manganese. It allows the fungus to outcompete other microorganisms for this ecological niche [46]. This is due to formation of highly stabile biogenic oxalates that decrease the exposure of microorganisms to potentially toxic manganese [47] or other metals [48]. This is also highlighted by our results, since the formation of manganese oxalates were shown to alleviate the stress related to the bioextraction of manganese. This has manifested in both $\mathrm{Mn}(\mathrm{II})$ and $\mathrm{Mn}(\mathrm{IV})$-oxides treatments (Figure 2). There, the growth of the fungus was initially inhibited (in comparison to the manganese-free control). However, after the formation of manganese oxalates, the growth was restored and the final dry biomasses' weights were comparable to the control. Still, since the detectable amounts of acetate were recorded in media treated with Mn(IV)-oxide, where the presence of manganese oxalate was most noticeable, we hypothesized that the formation of biogenic phases associated with fungal biomass (Figure 9) might also have a negative impact on fungal metabolism or cell integrity. Ruijter et al. [30] reported that the acetate should be consumed sufficiently fast to prevent its accumulation. This suggests that the overproduction of acetate along with the oxalate via oxalacetate cleavage took place, and while oxalate was being incorporated into growing crystals, the acetate needed to be extruded to lighten the burden on the cell. Alternatively, the growing crystal may have physically deformed the cell membrane, resulting in leakage of acetate (alongside the other metabolites) into the culture medium.

The noted manganese recrystallization is also a potential problem for the commercial application of low-grade ores' bioleaching by filamentous fungi since it can hinder the bioextraction performance due to undesirable manganese immobilization into a biogenic thermodynamically stable mineral (e.g., lindbergite). Still, Li et al. [49] reported that the manganese biomineralization can be also a useful strategy for the synthesis of novel electrode materials.

\section{Conclusions}

Our experimental observations confirmed that filamentous fungus $A$. niger was capable of dissolving all naturally occurring manganese oxides ( $\mathrm{MnO}, \mathrm{MnO} \cdot \mathrm{Mn}_{2} \mathrm{O}_{3}, \mathrm{Mn}_{2} \mathrm{O}_{3}$, $\mathrm{MnO}_{2}$ ) and that it can act as a geoactive agent regarding manganese transformation and mobilization in the environment. We have successfully simulated the process of fungal deterioration of $\mathrm{Mn}(\mathrm{II}), \mathrm{Mn}(\mathrm{II}, \mathrm{III}), \mathrm{Mn}(\mathrm{III})$ and $\mathrm{Mn}(\mathrm{IV})$-oxide minerals via mechanisms of acidolysis, complexolysis and reductive dissolution. Through the metabolic activity, the fungus $A$. niger showed the ability to condition the cultivation system to the extent that it resulted in the transformation of manganese into mycogenic mineral. This should inherently affect the stability of manganese oxides present in geochemical barriers, and the migration and distribution of other elements associated with their surfaces. Therefore, further research on the sorption properties of the natural manganese oxides and their transformants is required to better understand the environmental impact of fungal bioleaching. Thus, our results highlight the importance of fungi in biogeochemical cycling and the environmental behavior of manganese, and provide insight into the actual process of manganese oxides' biodeterioration. 
Author Contributions: Methodology, F.P. and M.U.; formal analysis, M.B., O.Z., E.D., M.C. and H.K.; investigation, B.F., M.M. and Z.K.; writing—original draft preparation, B.F.; writing-review and editing, M.U., M.D. and P.M.; visualization, M.C.; funding acquisition, M.U. All authors have read and agreed to the published version of the manuscript.

Funding: This research was funded by the Scientific Grant Agency of the Slovak Republic Ministry of Education and the Slovak Academy of Sciences, grant number 1/0146/18, by European Regional Development Fund-Project "Centre for Advanced Applied Sciences" grant number CZ.02.1.01/0.0/0.0/ 16_019/0000778, and by Comenius University in Bratislava under the contract No. UK/166/2021.

Institutional Review Board Statement: Not applicable.

Informed Consent Statement: Not applicable.

Data Availability Statement: Data is contained within the article.

Acknowledgments: We acknowledge DESY (Hamburg, Germany), a member of the Helmholtz Association HGF, for the provision of experimental facilities.

Conflicts of Interest: The authors declare no conflict of interest.

\section{References}

1. Gilkes, R.J.; McKenzie, R.M. Geochemistry and Mineralogy of Manganese in Soils. In Manganese in Soils and Plants, Proceedings of the International Symposium on 'Manganese in Soils and Plants', Adelaide, Australia, 22-26 August 1988; Graham, R.D., Hannam, R.J., Uren, N.C., Eds.; Springer: Dordrecht, The Netherlands, 1988; pp. 23-35.

2. Tebo, B.M.; Bargar, J.R.; Clement, B.G.; Dick, G.J.; Murray, K.J.; Parker, D.; Verity, R.; Webb, S.M. Biogenic manganese oxides: Properties and mechanisms of formation. Annu. Rev. Earth Planet. Sci. 2004, 32, 287-328. [CrossRef]

3. Robson, A.D. Manganese in Soils and Plants-An Overview. In Manganese in Soils and Plants, Proceedings of the International Symposium on 'Manganese in Soils and Plants', Adelaide, Australia, 22-26 August 1988; Graham, R.D., Hannam, R.J., Uren, N.C., Eds.; Springer: Dordrecht, The Netherlands, 1988; pp. 329-333.

4. Baranowski, R.; Rybak, A.; Baranowska, I. Speciation Analysis of Elements in Soil Samples by XRF. Pol. J. Environ. Stud. 2002, 11, 473-482.

5. Baranowski, R.; Rybak, A.; Sobczyński, T. X-ray Fluorescence Spectrometry in Speciation Analysis of Bottom Sediments. J. Environ. Stud. 2001, 10, 297-306.

6. Zerbe, J.; Sobczyński, T.; Elbanowska, H.; Siepak, J. Speciation of heavy metals in bottom sediments of lakes. Pol. J. Environ. Stud. 1999, 8, 331-339.

7. Remucal, C.K.; Ginder-Vogel, M. A critical review of the reactivity of manganese oxides with organic contaminants. Environ. Sci. Process. Impacts 2014, 16, 1247-1266. [CrossRef] [PubMed]

8. Archibald, F.S.; Fridovich, I. Manganese and defenses against oxygen toxicity in Lactobacillus plantarum. J. Bacteriol. 1981, 145, 442-451. [CrossRef] [PubMed]

9. Fernando, D.R.; Lynch, J.P. Manganese phytotoxicity: New light on an old problem. Ann. Bot. 2015, 116, 313-319. [CrossRef] [PubMed]

10. Culotta, V.C.; Yang, M.; Hall, M.D. Manganese transport and trafficking: Lessons learned from Saccharomyces cerevisiae. Eukaryot. Cell 2005, 4, 1159-1165. [CrossRef] [PubMed]

11. Perel'man, A.I. Geochemical barriers: Theory and practical applications. Appl. Geochem. 1986, 1, 669-680. [CrossRef]

12. Hagarová, I. Utilization of biosurfactants in remediation of environmental media contaminated with heavy metals. Chem. Listy 2015, 109, 431-436.

13. Hagarová, I. Extractions complying with the principles of green chemistry used in trace analysis of metals. Chem. Listy 2015, 109, 269-275.

14. Boriová, K.; Urík, M.; Bujdoš, M.; Pifková, I.; Matúš, P. Chemical mimicking of bio-assisted aluminium extraction by Aspergillus niger's exometabolites. Environ. Pollut. 2016, 218, 281-288. [CrossRef]

15. Zwietering, M.H.; Jongenburger, I.; Rombouts, F.M.; van't Riet, K. Modeling of the bacterial growth curve. Appl. Environ. Microbiol. 1990, 56, 1875-1881. [CrossRef]

16. Sádecká, J.; Polonský, J. Determination of organic acids in tobacco by capillary isotachophoresis. J. Chromatogr. A 2003, 988, 161-165. [CrossRef]

17. Farkas, B.; Kolenčík, M.; Hain, M.; Dobročka, E.; Kratošová, G.; Bujdoš, M.; Feng, H.; Deng, Y.; Yu, Q.; Illa, R.; et al. Aspergillus niger decreases bioavailability of arsenic $(\mathrm{V})$ via biotransformation of manganese oxide into biogenic oxalate minerals. J. Fungi 2020, 6, 270. [CrossRef] [PubMed]

18. Urík, M.; Farkas, B.; Miglierini, M.B.; Bujdoš, M.; Mitróová, Z.; Kim, H.; Matúš, P. Mobilisation of hazardous elements from arsenic-rich mine drainage ochres by three Aspergillus species. J. Hazard. Mater. 2021, 409, 124938. [CrossRef] [PubMed] 
19. Grangeon, S.; Bataillard, P.; Coussy, S. The Nature of Manganese Oxides in Soils and Their Role as Scavengers of Trace Elements: Implication for Soil Remediation. In Environmental Soil Remediation and Rehabilitation: Existing and Innovative Solutions; van Hullebusch, E.D., Huguenot, D., Pechaud, Y., Simonnot, M.-O., Colombano, S., Eds.; Springer International Publishing: Cham, Switzerland, 2020; pp. 399-429.

20. Farkas, B.; Urík, M.; Matúš, P. Manganese biotransformation by microorganisms. Chem. Listy 2020, 114, 841-846.

21. Das, A.P.; Sukla, L.B.; Pradhan, N.; Nayak, S. Manganese biomining: A review. Bioresour. Technol. 2011, 102, 7381-7387. [CrossRef]

22. Acharya, C.; Kar, R.N.; Sukla, L.B. Studies on reaction mechanism of bioleaching of manganese ore. Miner. Eng. 2003, 16, 1027-1030. [CrossRef]

23. Mehta, K.D.; Das, C.; Pandey, B.D. Leaching of copper, nickel and cobalt from Indian Ocean manganese nodules by Aspergillus niger. Hydrometallurgy 2010, 105, 89-95. [CrossRef]

24. Keshavarz, S.; Faraji, F.; Rashchi, F.; Mokmeli, M. Bioleaching of manganese from a low-grade pyrolusite ore using Aspergillus niger: Process optimization and kinetic studies. J. Environ. Manag. 2021, 285, 112153. [CrossRef] [PubMed]

25. Kim, M.-J.; Seo, J.-Y.; Choi, Y.-S.; Kim, G.-H. Bioleaching of spent Zn-Mn or Ni-Cd batteries by Aspergillus species. Waste Manag. 2016, 51, 168-173. [CrossRef] [PubMed]

26. Polák, F.; Urík, M.; Matúš, P. Low molecular weight organic acids in soil environment. Chem. Listy 2019, 113, 307-314.

27. Bagar, T.; Altenbach, K.; Read, N.D.; Bencina, M. Live-Cell imaging and measurement of intracellular $\mathrm{pH}$ in filamentous fungi using a genetically encoded ratiometric probe. Eukaryot. Cell 2009, 8, 703-712. [CrossRef]

28. Serrano, R. Structure and function of proton translocating ATPase in plasma membranes of plants and fungi. Biochim. Biophys. Acta Rev. Biomembr. 1988, 947, 1-28. [CrossRef]

29. Urík, M.; Polák, F.; Bujdoš, M.; Pifková, I.; Kořenková, L.; Littera, P.; Matúš, P. Aluminium Leaching by Heterotrophic Microorganism Aspergillus niger: An Acidic Leaching? Arab. J. Sci. Eng. 2018, 43, 2369-2374. [CrossRef]

30. Ruijter, G.J.G.; van de Vondervoort, P.J.I.; Visser, J. Oxalic acid production by Aspergillus niger: An oxalate-non-producing mutant produces citric acid at $\mathrm{pH} 5$ and in the presence of manganese. Microbiology 1999, 145, 2569-2576. [CrossRef]

31. Xyla, A.G.; Sulzberger, B.; Luther, G.W.; Hering, J.G.; Van Cappellen, P.; Stumm, W. Reductive dissolution of manganese(III, IV) (hydr)oxides by oxalate: The effect of $\mathrm{pH}$ and light. Langmuir 1992, 8, 95-103. [CrossRef]

32. Miyata, N.; Tani, Y.; Iwahori, K.; Soma, M. Enzymatic formation of manganese oxides by an Acremonium-like hyphomycete fungus, strain KR21-2. FEMS Microbiol. Ecol. 2004, 47, 101-109. [CrossRef]

33. Höfer, C.; Schlosser, D. Novel enzymatic oxidation of $\mathrm{Mn}^{2+}$ to $\mathrm{Mn}^{3+}$ catalyzed by a fungal laccase. FEBS Lett. 1999, 451, 186-190. [CrossRef]

34. Zeiner, C.A.; Purvine, S.O.; Zink, E.; Wu, S.; Paša-Tolić, L.; Chaput, D.L.; Santelli, C.M.; Hansel, C.M. Mechanisms of Manganese(II) Oxidation by Filamentous Ascomycete Fungi Vary with Species and Time as a Function of Secretome Composition. Front. Microbiol. 2021, 12, 81. [CrossRef]

35. Tang, Y.; Zeiner, C.A.; Santelli, C.M.; Hansel, C.M. Fungal oxidative dissolution of the Mn(II)-bearing mineral rhodochrosite and the role of metabolites in manganese oxide formation. Environ. Microbiol. 2013, 15, 1063-1077. [CrossRef]

36. Johnson, D.B.; Pakostova, E. Dissolution of Manganese (IV) Oxide Mediated by Acidophilic Bacteria, and Demonstration That Manganese (IV) Can Act as Both a Direct and Indirect Electron Acceptor for Iron-Reducing Acidithiobacillus spp. Geomicrobiol. J. 2021, 38, 570-576. [CrossRef]

37. Wei, Z.; Hillier, S.; Gadd, G.M. Biotransformation of manganese oxides by fungi: Solubilization and production of manganese oxalate biominerals. Environ. Microbiol. 2012, 14, 1744-1753. [CrossRef]

38. Gadd, G.M. Metals, minerals and microbes: Geomicrobiology and bioremediation. Microbiology 2010, 156, 609-643. [CrossRef]

39. Das, A.P.; Swain, S.; Panda, S.; Pradhan, N.; Sukla, L.B. Reductive Acid Leaching of Low Grade Manganese Ores. Geomaterials 2012, 2, 70-72. [CrossRef]

40. Karaffa, L.; Kubicek, C. Production of Organic Acids by Fungi. In The Mycota. Industrial Applications; Hofrichter, M., Ed.; Springer: Berlin/Heidelberg, Germay, 2020; pp. 215-234.

41. Šimonovičová, A.; Kupka, D.; Nosalj, S.; Kraková, L.; Drahovská, H.; Bártová, Z.; Vojtková, H.; Boturová, K.; Pangallo, D. Differences in metabolites production using the Biolog FF Microplate ${ }^{\mathrm{TM}}$ system with an emphasis on some organic acids of Aspergillus niger wild type strains. Biologia 2020, 75, 1537-1546. [CrossRef]

42. Show, P.L.; Oladele, K.O.; Siew, Q.Y.; Aziz Zakry, F.A.; Lan, J.C.-W.; Ling, T.C. Overview of citric acid production from Aspergillus niger. Front. Life Sci. 2015, 8, 271-283. [CrossRef]

43. Ahmed, A.S.; Farag, S.S.; Hassan, I.A.; Botros, H.W. Production of gluconic acid by using some irradiated microorganisms. J. Radiat. Res. Appl. Sci. 2015, 8, 374-380. [CrossRef]

44. Schmitz, K.; Peter, V.; Meinert, S.; Kornfeld, G.; Hardiman, T.; Wiechert, W.; Noack, S. Simultaneous utilization of glucose and gluconate in Penicillium chrysogenum during overflow metabolism. Biotechnol. Bioeng. 2013, 110, 3235-3243. [CrossRef]

45. Ferrier, J.; Yang, Y.; Csetenyi, L.; Gadd, G.M. Colonization, penetration and transformation of manganese oxide nodules by Aspergillus niger. Environ. Microbiol. 2019, 21, 1821-1832. [CrossRef]

46. Fomina, M.; Hillier, S.; Charnock, J.M.; Melville, K.; Alexander, I.J.; Gadd, G.M. Role of Oxalic Acid Overexcretion in Transformations of Toxic Metal Minerals by Beauveria caledonica. Appl. Environ. Microbiol. 2005, 71, 371-381. [CrossRef]

47. Cheung, H.Y.; Vitkovič, L.; Brown, M.R.W. Toxic Effect of Manganese on Growth and Sporulation of Bacillus stearothermophilus. Microbiology 1982, 128, 2395-2402. [CrossRef] 
48. Green Iii, F.; Clausen, C.A. Copper tolerance of brown-rot fungi: Time course of oxalic acid production. Int. Biodeterior. Biodegrad. 2003, 51, 145-149. [CrossRef]

49. Li, Q.; Liu, D.; Jia, Z.; Csetenyi, L.; Gadd, G.M. Fungal Biomineralization of Manganese as a Novel Source of Electrochemical Materials. Curr. Biol. 2016, 26, 950-955. [CrossRef] 